\title{
Extraction, Characterization and Immunological Activity of Polysaccharides from Rhizoma gastrodiae
}

\author{
Juncheng Chen ${ }^{1}$, Shan Tian ${ }^{1}$, Xiaoying Shu ${ }^{1}$, Hongtao $\mathrm{Du}^{1,2}{ }^{1,} \mathrm{Na} \mathrm{Li}^{1}$ and Junru Wang ${ }^{1, *}$ \\ 1 Shaanxi Key Laboratory of Natural Products \& Chemical Biology, College of Sciences, \\ Northwest A \& F University, Yangling 712100, Shaanxi, China; cjc2009@nwsuaf.edu.cn (J.C.); \\ stian@nwsuaf.edu.cn (S.T.); shuxiaoying1@163.com (X.S.); duht@nwsuaf.edu.cn (H.D.); \\ lnuk@nwsuaf.edu.cn (N.L.) \\ 2 College of Plant Protection, Northwest A \& F University, Yangling 712100, Shaanxi, China \\ * Correspondence: wangjunru@nwsuaf.edu.cn; Tel./Fax: +86-29-8709-2829
}

Academic Editor: Charles Brennan

Received: 12 May 2016; Accepted: 6 June 2016; Published: 25 June 2016

\begin{abstract}
A response surface and Box-Behnken design approach was applied to augment polysaccharide extraction from the residue of Rhizoma gastrodiae. Statistical analysis revealed that the linear and quadratic terms for three variables during extraction exhibited obvious effects on extraction yield. The optimum conditions were determined to be a liquid-to-solid ratio of $54 \mathrm{~mL} / \mathrm{g}$, an extraction temperature of $74{ }^{\circ} \mathrm{C}$, an extraction time of $66 \mathrm{~min}$, and three extractions. These conditions resulted in a maximum Rhizoma gastrodiae polysaccharide (RGP) extraction yield of $6.11 \% \pm 0.13 \%$. Two homogeneous polysaccharides (RGP-1a and RGP-1b) were obtained using DEAE cellulose- 52 and Sephadex G-100 columns. The preliminary characterization of RGP-1a and RGP-1b was performed using HPLC-RID, HPGPC, and FTIR. Tests of the immunological activity in vitro showed that the two polysaccharides could significantly stimulate macrophages to release $\mathrm{NO}$ and enhance phagocytosis in a dose-dependent manner. In particular, RGP-1b $(200 \mu \mathrm{g} / \mathrm{mL})$ and LPS $(2 \mu \mathrm{g} / \mathrm{mL})$ had almost the same influence on the NO production and phagocytic activity of RAW 264.7 macrophages $(p>0.05)$. All the data obtained indicate that RGP-1a and RGP-1b have the potential to be developed as a health food.
\end{abstract}

Keywords: Rhizoma gastrodiae; polysaccharides; optimized extraction; characterization; immunological activity

\section{Introduction}

Polysaccharides constitute long chains or molecular strands of monosaccharides connected by glycosidic linkages. These polymeric carbohydrate arrangements are found almost exclusively in animals, plants, and microbes. Polysaccharides from plants have diverse bioactivity and high safety in human beings, and the isolation of polysaccharides from herbal or agricultural material has become an important area of research. A number of studies have shown that polysaccharides have various medicinal properties, including immunological [1-3], anti-cancer [4-6], anti-oxidant [7-9], anti-inflammatory $[10,11]$ and hypoglycemic activity $[12,13]$.

Rhizoma gastrodiae (called Tianma in Chinese) is the dried rhizome of Gastrodiaelata Blume (Orchidaceae). In China, it is used as both a traditional medicine and a food because of its diverse biological activity. For centuries, it has been used to treat convulsion, neurasthenia, headache, ischemia, vertigo, dementia, and hemiplegia [14-17]. Phenolic compounds, such as gastrodin, 4-hydroxybenzyl alcohol and parishin B, are the main bioactive constituents of rhizoma gastrodiae [18-20], and recent research has indicated that Rhizoma gastrodiae polysaccharide (RGP) is also an important active substance. Ming's team [21] isolated the polysaccharide PGEB-3H from Rhizoma gastrodiae and found 
that it has hypolipidemic activity, while Chen's group [22] reported that a RGP has anti-cancer activity. After phenolic compounds are extracted from Rhizoma gastrodiae, the raw residue is discarded, which might be a useful polysaccharides resource as it contains plenty of RGP. Although some studies have been done on RGP, reports on the structure and activity of this polysaccharide are limited.

Therefore, to enhance RGP resource efficiency, we applied response surface methodology (RSM) to improve polysaccharide extraction from Rhizoma gastrodiae residue, and to provide more evidence to support the use of RGP in the food industry. In addition, basic structural characterizations of RGP-1a and RGP- $1 b$ were under taken using a combination of chemical and instrumental analyses, and the immunological activity of RGP-1a and RGP-1b was examined further.

\section{Results and Discussion}

\subsection{Single-Factor Experimental Analysis}

\subsubsection{Effect of Extraction Time on the Yield of Rhizoma gastrodiae Polysaccharide (RGP)}

The effect of different extraction times $(10,30,50,70$ and $90 \mathrm{~min})$ on the extraction yield of RGP was determined, with the other extraction parameters fixed as follows: the liquid-to-solid ratio was $30 \mathrm{~mL} / \mathrm{g}$, the extraction temperature was $60^{\circ} \mathrm{C}$, and the number of extractions was two. As shown in Figure 1A, the yield significantly increased when the extraction time was increased from 10 to $50 \mathrm{~min}$. However, the yield decreased when the extraction time was above $70 \mathrm{~min}$, because too long an extraction time can lead to degradation of polysaccharide [23]. So, the favored extraction time is 40-70 min.

\subsubsection{Effect of Extraction Temperature on the Yield of RGP}

We determined the RGP extraction yield under a series of different extraction temperatures $\left(30,40,50,60,70,80\right.$ and $\left.90{ }^{\circ} \mathrm{C}\right)$, but fixed liquid-to-solid ratio $(30 \mathrm{~mL} / \mathrm{g})$ and water extraction time $(60 \mathrm{~min})$, with extractions performed in duplicate. As shown in Figure 1B, the yield gradually increased as the extraction temperature rose from 30 to $80^{\circ} \mathrm{C}$, after which there was no significant change. The extraction coefficient is enhanced by a higher extraction temperature due to an increase in polysaccharide solubility [24]. An extraction temperature range of $50-80^{\circ} \mathrm{C}$ was thus considered to be optimum.

\subsubsection{Effect of the Liquid-to-Solid Ratio on the Yield of RGP}

The liquid-to-solid ratio significantly affects the extraction yield of RGP. A low ratio can result in incomplete polysaccharide extraction, whereas a high ratio can lead to increased process costs. We determined the RGP extraction yield under a series of liquid-to-solid ratios (10, 20, 30, 40, 50 and $60 \mathrm{~mL} / \mathrm{g})$, but fixed extraction time $(60 \mathrm{~min})$ and temperature $\left(60^{\circ} \mathrm{C}\right)$, with extractions performed in duplicate. As shown in Figure 1C, extraction yield increased considerably with the increase in the liquid-to-solid ratio (10-40 mL/g), but no obvious change was observed when the ratio was further increased. Based on these results, a range of $30-60 \mathrm{~mL} / \mathrm{g}$ was applied in our work.

\subsubsection{Effect of the Number of Extractions on the Yield of RGP}

The efficiency of different numbers of extractions (1-5) on the extraction yield of RGP was investigated, with the other extraction conditions fixed as follows: extraction temperature $60{ }^{\circ} \mathrm{C}$, extraction time $30 \mathrm{~min}$, and liquid-to-solid ratio $30 \mathrm{~mL} / \mathrm{g}$. The results (Figure 1D) show that the extraction yield of RGP increases as the number of extractions is increased from one to three, but there is no further increase with additional extractions. Therefore, the optimum number of extractions is three. 
A

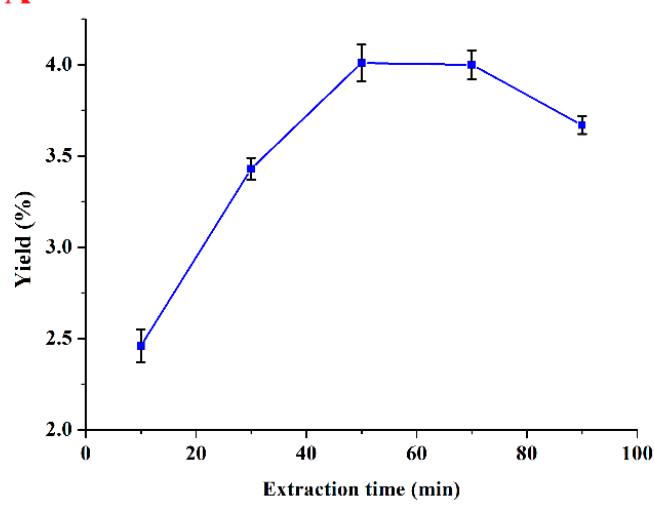

C

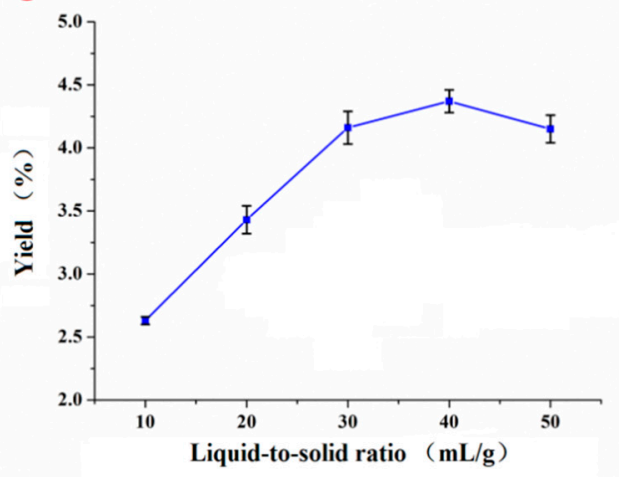

E

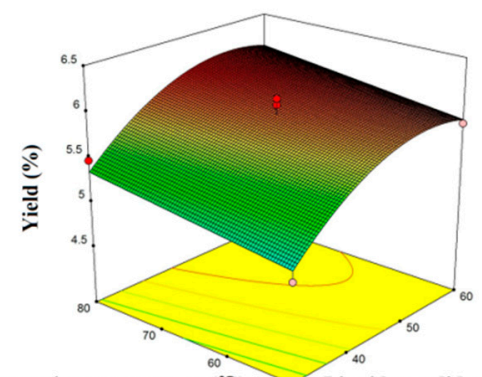

Extraction temperature $\left({ }^{\circ} \mathrm{C}\right) \quad{ }_{50} 30$ Liquid-to-solid ratio $(\mathrm{mL} / \mathrm{g})$
B

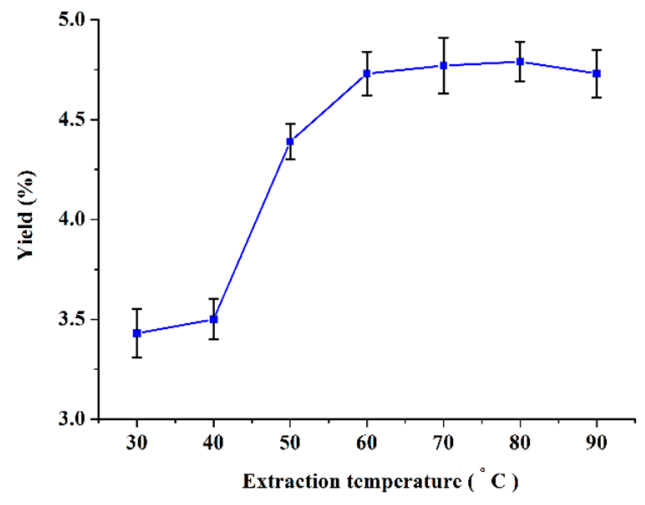

D

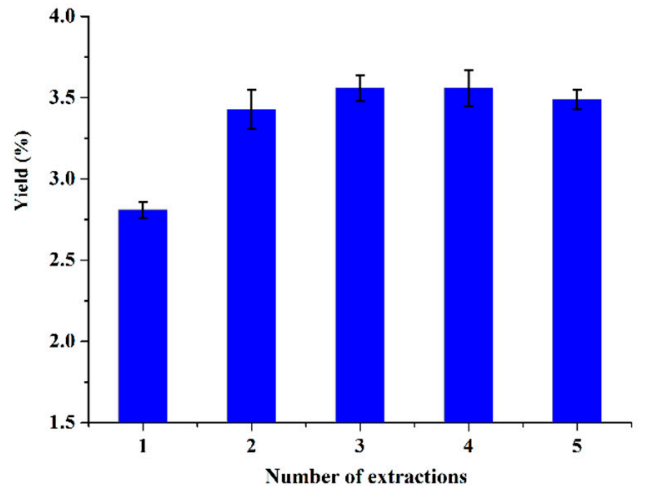

F

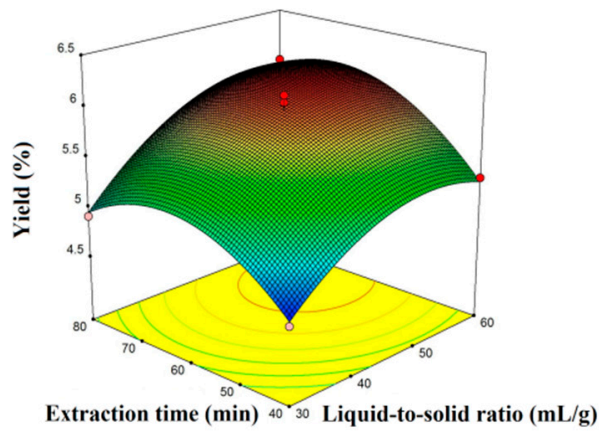

G

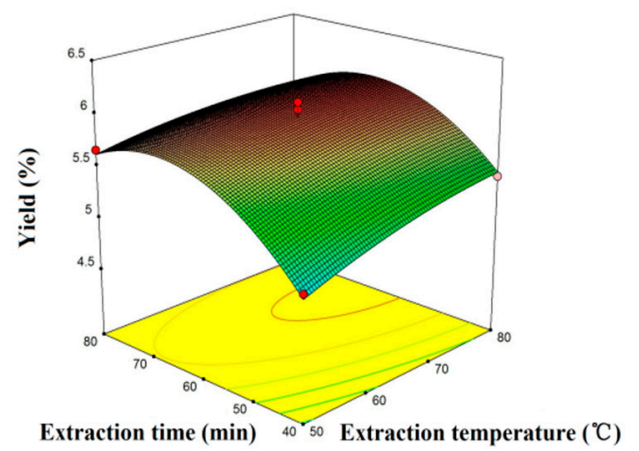

Figure 1. Effects of extraction time (A); extraction temperature (B); liquid-to-solid ratio; (C) and number of extractions (D) on the extraction yield of RGP. Each value is presented as mean \pm S.D. $(n=3)$; Response surface (3D) showing the effects of extraction temperature and liquid-to-solid ratio at a fixed extraction time of $60 \mathrm{~min}(\mathrm{E})$; extraction time and liquid-to-solid ratio at a fixed extraction temperature $65{ }^{\circ} \mathrm{C}(\mathrm{F})$; extraction time and extraction temperature at a fixed liquid-to-solid ratio of $45 \mathrm{~mL} / \mathrm{g}$ on extraction yield of RGP $(\mathbf{G})$. 


\subsubsection{Optimum Conditions for the RSM Experiments}

The single-factor experimental analysis indicated that the optimum conditions for the RSM experiments are an extraction time of $40-70 \mathrm{~min}$, an extraction temperature of $50-80^{\circ} \mathrm{C}$, a liquid-to-solid ratio of $30-60 \mathrm{~mL} / \mathrm{g}$ and three extractions.

\subsection{Optimization of the RGP Extraction}

\subsubsection{Predicted Model and Statistical Analysis}

The Box-Behnken design matrix and the results of the RSM experiments carried out to determine the effects of the three independent variables are given in Table 1. By applying multiple regression analysis to the experimental data, the response variable $(Y)$ can be characterized by the following second-order polynomial equation:

$$
Y=5.95+0.39 X_{1}+0.15 X_{2}+0.25 X_{3}-0.08 X_{1} X_{2}+0.095 X_{1} X_{3}-0.075 X_{2} X_{3}-0.33 X_{1}^{2}-0.075 X_{2}^{2}-0.43 X_{3}^{2}
$$

where $Y$ is the extraction yield (\%) of RGP, and $X_{1}, X_{2}$ and $X_{3}$ are the coded variables for the liquid-to-solid ratio, extraction temperature, and extraction time, respectively.

Table 1. The BBD matrix and response values for the extraction yield of Rhizoma gastrodiae Polysaccharide (RGP).

\begin{tabular}{ccccc}
\hline Run & $\begin{array}{c}\boldsymbol{X}_{\mathbf{1}} \\
\text { (Liquid-to-Solid Ratio, } \mathbf{~ m L} / \mathbf{g})\end{array}$ & $\begin{array}{c}\boldsymbol{X}_{\mathbf{2}} \\
\left.\text { (Extraction Temperature, }{ }^{\circ} \mathbf{C}\right)\end{array}$ & $\begin{array}{c}\boldsymbol{X}_{\mathbf{3}} \\
\text { (Extraction Time, } \mathbf{m i n})\end{array}$ & Yield of RGP (\%) \\
\hline 1 & $1(60)$ & $-1(50)$ & $0(60)$ & 5.78 \\
2 & $-1(30)$ & $0(65)$ & $1(80)$ & 4.91 \\
3 & $0(45)$ & $0(65)$ & $0(60)$ & 5.84 \\
4 & $-1(30)$ & $0(65)$ & $-1(40)$ & 4.59 \\
5 & $0(45)$ & $0(65)$ & $0(60)$ & 6.03 \\
6 & $1(60)$ & $0(65)$ & $1(80)$ & 5.97 \\
7 & $-1(30)$ & $1(80)$ & $0(60)$ & 5.47 \\
8 & $0(45)$ & $0(65)$ & $0(60)$ & 6.91 \\
9 & $0(45)$ & $0(65)$ & $0(60)$ & 6.01 \\
10 & $1(60)$ & $1(80)$ & $0(60)$ & 5.01 \\
11 & $0(45)$ & $-1(50)$ & $-1(40)$ & 5.73 \\
12 & $0(45)$ & $1(80)$ & $1(80)$ & 5.89 \\
13 & $0(45)$ & $0(65)$ & $0(60)$ & 5.66 \\
14 & $0(45)$ & $-1(50)$ & $1(80)$ & 5.38 \\
15 & $0(45)$ & $1(80)$ & $-1(40)$ & 5.27 \\
16 & $1(60)$ & $0(65)$ & $-1(40)$ & 4.92 \\
\hline
\end{tabular}

We used analysis of variance (ANOVA) to determine the appropriateness of the proposed model and identify the significant factors from the four. The results showed that the predicted model can be summarized as in Table 2. The $R^{2}$ and $R^{2}$ adj values for the model (0.9784 and 0.9507, respectively) did not differ greatly, which indicated close agreement between the experimental results and the theoretical values obtained using the polynomial model. A low $p$ value $(p<0.0001)$ confirmed that the model could represent the actual relationship between the parameters and the response with significance. Furthermore, the model exhibited a high degree of accuracy, consistency, and reproducibility, as evidenced by the calculated coefficient of variation $(1.86 \%)$.

The $p$ values were used as a tool to evaluate the significance of each coefficient. The smaller the $p$ value, the more significant the corresponding coefficient [25]. As can be seen in Table 2, the coefficients for the linear terms $\left(X_{1}, X_{2}\right.$ and $\left.X_{3}\right)$ and the quadratic terms $\left(X_{1}^{2}\right.$ and $\left.X_{3}^{2}\right)$ were highly significant $(p<0.01)$. The coefficients for the other terms were not significant $(p>0.05)$. 
Table 2. Analysis of variance (ANOVA) results of the regression model for the extraction yield of RGP.

\begin{tabular}{|c|c|c|c|c|c|c|}
\hline Source & Sum of Squares & Df & Mean Square & F-Value & $p$-Value & Significance \\
\hline Model & 3.41 & 9 & 0.38 & 35.28 & $<0.0001$ & $* *$ \\
\hline$X_{1}$ & 1.23 & 1 & 1.23 & 114.92 & $<0.0001$ & $* *$ \\
\hline$X_{2}$ & 0.19 & 1 & 0.19 & 17.35 & 0.0042 & $* *$ \\
\hline$X_{3}$ & 0.51 & 1 & 0.51 & 47.56 & 0.0002 & $* *$ \\
\hline$X_{1} X_{2}$ & 0.026 & 1 & 0.026 & 2.39 & 0.1663 & - \\
\hline$X_{1} X_{3}$ & 0.036 & 1 & 0.036 & 3.37 & 0.1092 & - \\
\hline$X_{2} X_{3}$ & 0.022 & 1 & 0.022 & 2.10 & 0.1908 & - \\
\hline$X_{1}^{2}$ & 0.47 & 1 & 0.47 & 43.93 & 0.0003 & ** \\
\hline$X_{2}^{2}$ & 0.023 & 1 & 0.023 & 2.18 & 0.1834 & - \\
\hline$X_{3}^{2}$ & 0.79 & 1 & 0.79 & 74.12 & $<0.0001$ & ** \\
\hline Residual & 0.075 & 7 & 0.011 & & & \\
\hline Lack of fit & 0.029 & 3 & 0.010 & 0.84 & 0.5398 & - \\
\hline Pure error & 0.046 & 4 & 0.012 & & & \\
\hline Cor. total & 3.48 & 16 & & & & \\
\hline \multicolumn{7}{|c|}{$\begin{array}{c}\text { C. } V . \%=1.86 \% \\
R^{2}=0.9784 \\
R^{2}{ }_{a d j}=0.9507\end{array}$} \\
\hline
\end{tabular}

\subsubsection{Analysis of the Response Surface}

The three-dimensional (3D) response surfaces were plotted using Design-Expert software (version 8.0.6, Statease, MN, USA) in order to study the effects of the parameters (liquid-to-solid ratio, extraction temperature, and extraction time) and their interactions on the extraction yield of RGP. The results are presented in Figure 1E-G.

Figure 1E shows the effect of the liquid-to-solid ratio and the extraction temperature on the extraction yield of RGP at a fixed extraction time of $60 \mathrm{~min}$. It can be seen that the maximum yield can be achieved when the liquid-to-solid ratio is $53.4 \mathrm{~mL} / \mathrm{g}$ and the extraction temperature is $73.5^{\circ} \mathrm{C}$.

Figure $1 \mathrm{~F}$ shows the $3 \mathrm{D}$ response surface plot of the extraction yield of RGP when varying the liquid-to-solid ratio and the extraction time but keeping the extraction temperature fixed at $65^{\circ} \mathrm{C}$. It can be observed that maximum yield was obtained at a liquid-to-solid ratio of $53.4 \mathrm{~mL} / \mathrm{g}$ and an extraction time of $66.1 \mathrm{~min}$.

Figure 1G shows the effects of extraction temperature and time on RGP yield at a liquid-to-solid ratio of $45 \mathrm{~mL} / \mathrm{g}$, under which maximum yield was reached at an extraction temperature of $73.5^{\circ} \mathrm{C}$ and extraction time of $66.1 \mathrm{~min}$.

\subsubsection{Verification of the Model}

To verify and validate the model equation, we performed five experiments to assess the optimal variables for extraction under a liquid-to-solid ratio of $54 \mathrm{~mL} / \mathrm{g}$, extraction time of $66 \mathrm{~min}$, and extraction temperature of $74{ }^{\circ} \mathrm{C}$. The extractions were carried out in triplicate. There was no significant difference $(p>0.05)$ between the experimentally determined mean yield $(6.11 \% \pm 0.13 \%)$ and the predicted yield $(6.15 \%)$. Therefore, the results suggest that the model is accurate and adequate for modeling the extraction of RGP.

\subsection{Purification and Preliminary Characterization of RGP}

\subsubsection{Purification, Homogeneity, and Molecular Weights of RGP-1a and RGP-1b}

The crude RGP was prepared using the optimal extraction conditions. It was then dissolved in distilled water and fractionated into three fractions (RGP-1, RGP-2, and RGP-3) using a DEAE 
cellulose-52 column (Figure 2A). The RGP-1 fraction was further separated using a Sephadex G-100 column, resulting in two fractions (RGP-1a and RGP-1b) (Figure 2B).

A
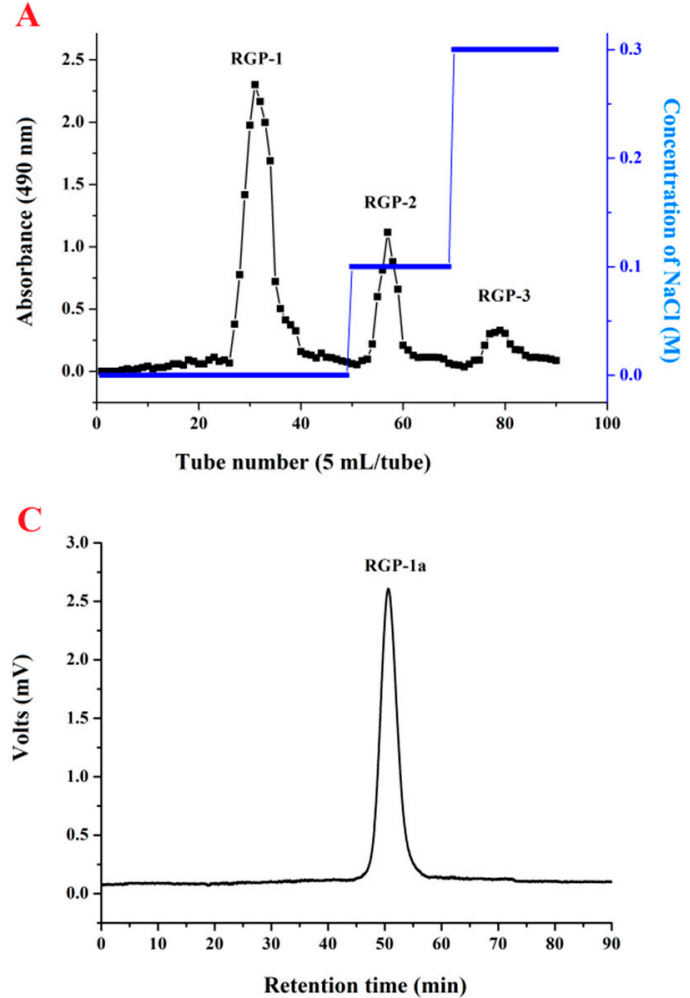

B

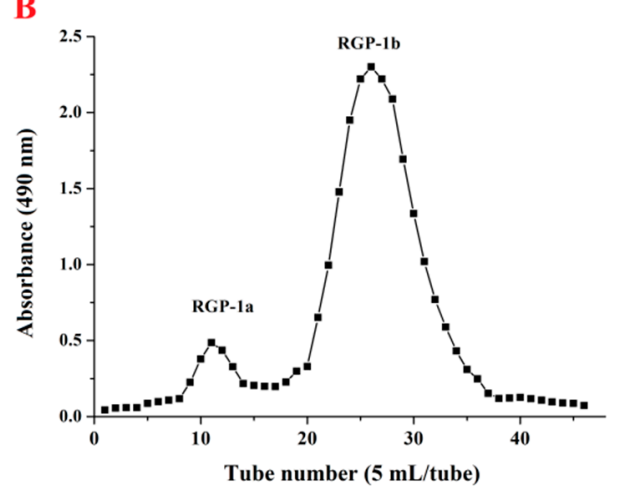

D

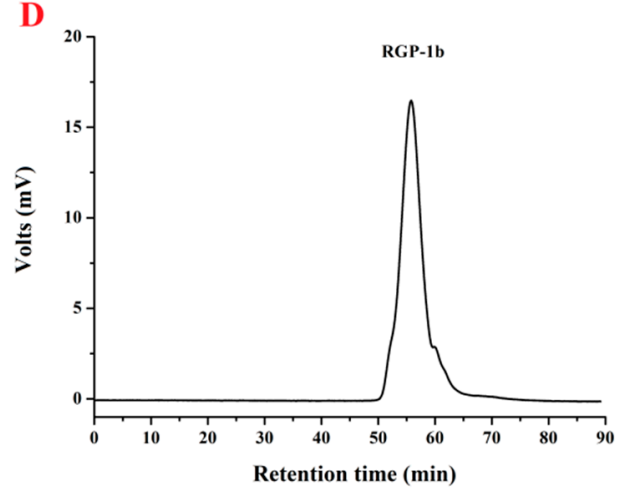

Figure 2. (A) Elution curve of crude RGP on DEAE-cellulose column; (B) elution curve of RGP-1 on Sephadex G-100 column; (C) HPGPC spectra of RGP-1a and (D) RGP-1b.

High-performance gel permeation chromatography (HPGPC) was used to determine the homogeneity and the molecular weights of RGP-1a and RGP-1b. As shown in Figure 2C,D, both RGP-1a and RGP- $1 \mathrm{~b}$ demonstrated a single and symmetrical peak, indicating that they were homogeneous polymers. Using the calibration curve, the average molecular weights of RGP-1a and RGP-1b were calculated to be 19.25 and $3.92 \mathrm{kDa}$, respectively. These molecular weights are lower than those of polysaccharides extracted from Rhizoma gastrodiae reported in the literature, 700 [22] and $28.8 \mathrm{kDa}$ [21], suggesting that RGP-1a and RGP-1b may be two novel polysaccharides from rhizome gastrodiae.

\subsubsection{Preliminary Characterization of RGP-1a and RGP-1b}

The carbohydrate content of RGP-1a and RGP-1b was $92.53 \%$ and $96.88 \%$, respectively, and the two polysaccharides were free of protein and uronic acid. The monosaccharide compositions of RGP-1a and RGP- $1 \mathrm{~b}$ were analyzed using high-performance liquid chromatography-refractive index detector (HPLC-RID)(Figure 3A-C).The results showed that RGP-1a was composed of fructose and glucose in a molar ratio of 1:10.68, and RGP-1b consisted mainly of glucose. To the authors' knowledge, it is the first time fructose is identified in this polymer. 
A

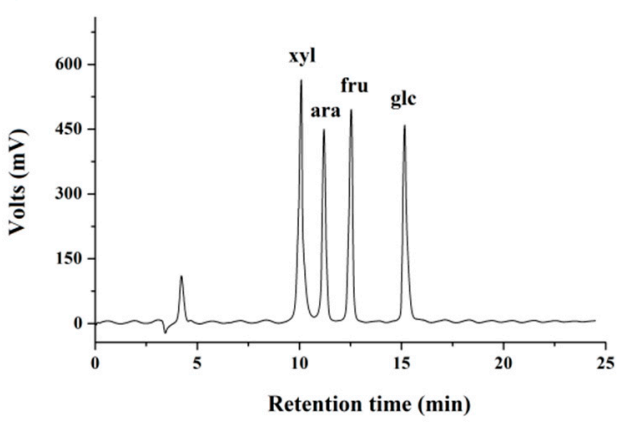

C

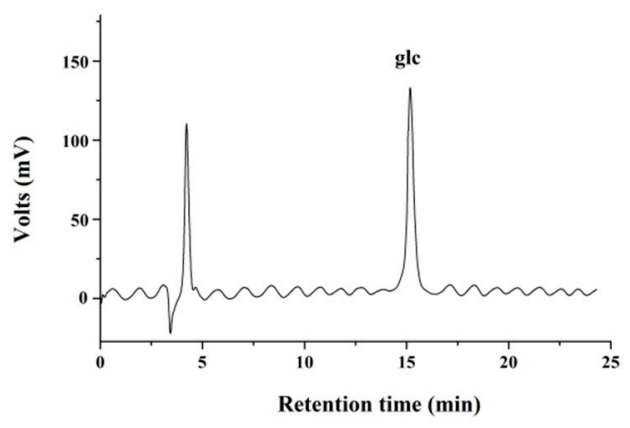

B

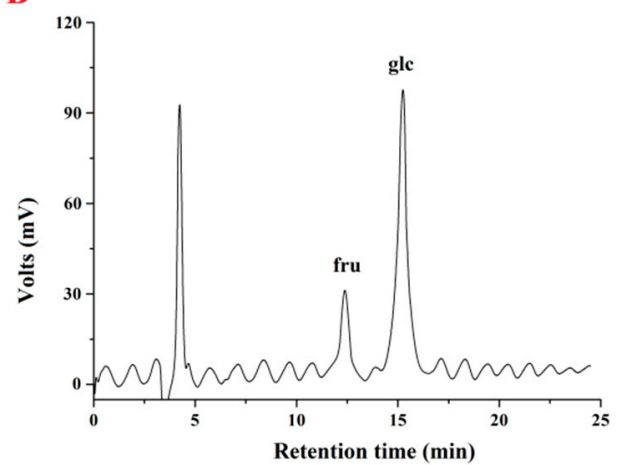

D

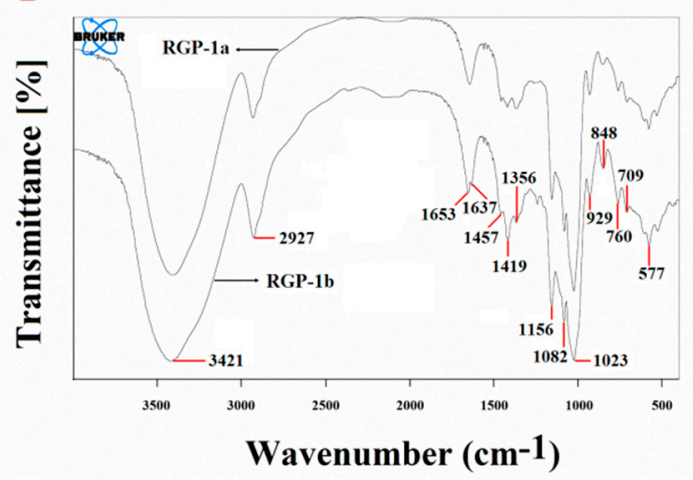

Figure 3. (A) HPLC spectra of standard monosaccharide; (B) RGP-1a; (C) RGP-1b and (D) FTIR spectra of RGP.

Fourier transform infrared (FTIR) spectra of RGP-1a and RGP-1b were recorded over the range of $400-4000 \mathrm{~cm}^{-1}$ (Figure 3D). The strong absorption peak around $3421 \mathrm{~cm}^{-1}$ and the band around $2927 \mathrm{~cm}^{-1}$ were attributed to the $-\mathrm{OH}$ and $\mathrm{C}-\mathrm{H}$ stretching vibrations, respectively. The absorption peak at around $1653 \mathrm{~cm}^{-1}$ is due to associated water [21,26]. The band in the region $1365-1457 \mathrm{~cm}^{-1}$ was attributed to the characteristic of $-\mathrm{OH}$ vibrations and $\mathrm{C}-\mathrm{H}$ bending vibrations. The absorption peaks at 1023, 1082 and $1156 \mathrm{~cm}^{-1}$ suggest the presence of $\mathrm{C}-\mathrm{O}-\mathrm{C}$ and $\mathrm{C}-\mathrm{O}-\mathrm{H}$ linkages, indicating a pyranose form of the glucosyl residue. Absorption at $929.0 \mathrm{~cm}^{-1}$ is typical of D-glucose in pyranose form. Moreover, the characteristic absorption bands at $848 \mathrm{~cm}^{-1}$ imply that the two purified fractions contain $\alpha$-glycosidic bonds [21].

\subsection{Effects of RGP-1a and RGP-1b on Macrophages in Vitro}

\subsubsection{Effects of RGP-1a and RGP-1b on Macrophage Viability}

Macrophages are a critical part of the natural immune defense system of hosts, which has various immune regulatory functions [27]. Therefore, it is important to know the cytotoxic effects of RGP-1a and RGP-1b on RAW 264.7 cells. As shown in Figure 4A, compared with the blank control, neither RGP-1a nor RGP-1b significantly affected the viability of RAW 264.7 cells over the whole concentration range of RGP analyzed (2.5-400 $\mu \mathrm{g} / \mathrm{mL})$. According to the research conducted by Zhang's team [28], this indicates that the two polysaccharides from RGP are not toxic to RAW 264.7 cells. Thus, both NO production and phagocytosis satisfactorily represented cell function without influencing cell quantity [28]. 
A

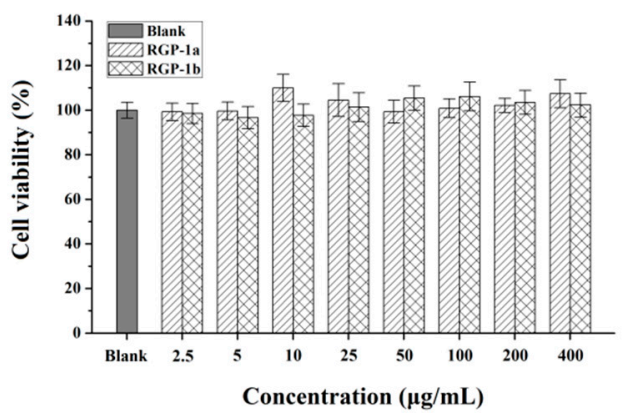

B

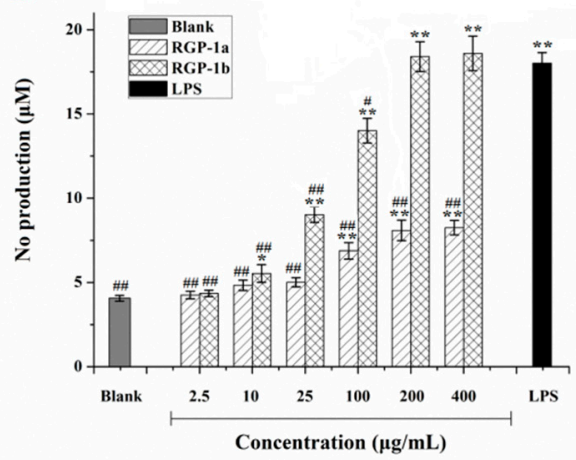

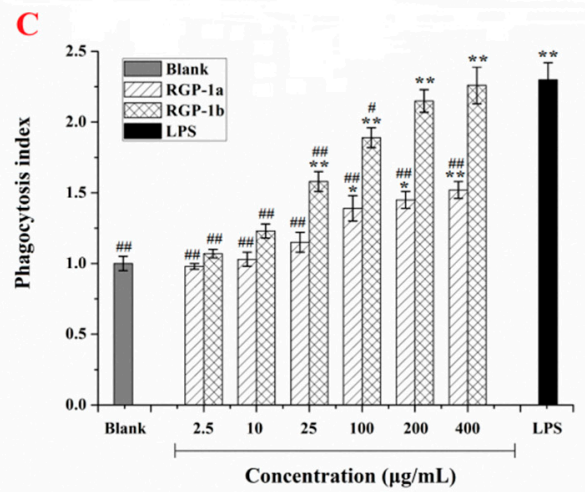

Figure 4. Effects of RGP-1a and RGP-1b on proliferation (A); NO production (B); and phagocytosis index (C) of RAW 264.7 cells. Cells were treated with RGP-1a and RGP-1b at various concentrations for $24 \mathrm{~h}$. The values are presented as mean \pm S.D. $(n=5) .{ }^{*} p<0.05,{ }^{* *} p<0.01$ compared with blank group; ${ }^{\#} p<0.05,{ }^{\#} p<0.01$ compared with LPS $(2 \mu \mathrm{g} / \mathrm{mL})$ group.

\subsubsection{Effects of RGP-1a and RGP-1b on Macrophage Activation}

The application of macrophage activation is a novel approach in immunotherapy disease treatment. Once macrophages are activated they can release a significant amount of $\mathrm{NO}$, which promotes tumor cell and pathogen death, and then acts as an intracellular messenger molecule to regulate numerous biological functions [29]. RAW 264.7 cells were treated with RGP-1a and RGP- $1 \mathrm{~b}$ at various concentrations and cultivted for $24 \mathrm{~h}$. As shown in Figure 4B, both RGP-1a and RGP-1b stimulated NO production in the cells in a dose-dependent manner. Compared with the blank control, the production of NO increased significantly $(p<0.05)$ with increasing concentrations of the two polysaccharides (100-400 $\mu \mathrm{g} / \mathrm{mL})$. Nevertheless, the effect of low concentrations of RGP-1a $(2.5-25 \mu \mathrm{g} / \mathrm{mL})$ was not significant $(p>0.05)$. Moreover, the production of NO when cells were treated with $200 \mu \mathrm{g} / \mathrm{mL}$ RGP-1b was equivalent to that seen with the positive control (lipopolysaccharide (LPS), $2 \mu \mathrm{g} / \mathrm{mL}$ ), which was better than the polysaccharides (ACPS-1 and ACPS-2) isolated from the roots of Actinidia Chinensis with $300 \mu \mathrm{g} / \mathrm{mL}$ [28]. The results confirm that the two polysaccharides activate macrophages and increase the production of NO in RAW 264.7 cells in a dose-dependent manner. This may be one of the reasons why RGP has antitumor activity.

\subsubsection{Effects of RGP-1a and RGP-1b Macrophages Phagocytosis}

As a defense response, macrophages can phagocytose (that is, envelop and destroy) foreign material as well as aging bacteria, damaged cells, and necrotic tissues, with phagocytic ability considered to be a strong indicator of macrophage activation [29]. In the present study, phagocytic activity of RAW 264.7 macrophages under RGP-1a and RGP-1b treatment was evaluated using the uptake of neutral red. The phagocytosis index (PI) of the two polysaccharides increased in a 
dose-dependent manner over the concentration range 2.5-400 $\mu \mathrm{g} / \mathrm{mL}$, the effect of RGP-1b being better than that of RGP-1a (Figure 4C). Nevertheless, compared with the blank control, the PIs of macrophages treated with lower concentrations of the polysaccharides were not significantly affected $(p<0.05)$. Furthermore, there was no significant difference $(p>0.05)$ between the PI for RGP-1b at a concentration of $200 \mu \mathrm{g} / \mathrm{mL}$ and the PI for the positive control (LPS, $10 \mu \mathrm{g} / \mathrm{mL}$ ). The results aresimilar to the effect of LP1 on the phagocytic ability of macrophages [30], which indicate that, within a certain concentration range, RGP-1a and RGP-1b significantly enhanced RAW 264.7 macrophage phagocytosis. This finding might relate to the two polysaccharides being bound by a particular receptor on the macrophage surface [31,32].

\section{Materials and Methods}

\subsection{Materials}

Rhizoma gastrodiae was purchased from the Shaanxi Han Wang Pharmaceutical Co. (Shaanxi, China). The samples were ground and passed through an 80-mesh sieve, and the Rhizoma gastrodiae powder preserved at $4{ }^{\circ} \mathrm{C}$. Lipopolysaccharide (LPS) sodium nitrite, 3-(4,5-dimethyltiazol-2-yl)-2,5 diphenyltetrazolium bromide (MTT) and Griess reagent (1\% sulfanilamide, $0.1 \% N$-(1-Naphthyl) ethylenediamine dihydrochloride and $2.5 \%$ phosphoric acid) were purchased from Sigma Chemical Co. (St. Louis, MO, USA). Neutral red and standard monosaccharides were obtained from Aladdin Chemical Reagent Co., Ltd. (Shanghai, China). RAW 264.7 cell lines were provided by the Polysaccharide Biological Functional Laboratory (Northwest A\&F University, Shaanxi, China). Trifluoroacetic acid (TFA, Sigma), dimethyl sulfoxide (DMSO, Sigma), ethyl alcohol (Sigma) and other reagents were all of analytical grade. High purity water was prepared in the authors' laboratory.

\subsection{Extraction and Determination of Polysaccharide}

Rhizoma gastrodiae powder was extracted three times with 75\% ethyl alcohol (\% v/v) over $24 \mathrm{~h}$. Subsequently, the residue was separated from the ethyl alcohol solvent by centrifugation $(3500 \times g$ for $10 \mathrm{~min}$ ) and dried at $60^{\circ} \mathrm{C}$ for $24 \mathrm{~h}$. The Rhizoma gastrodiae residue was extracted using water, and the optimized extraction time and temperature, liquid-to-solid ratio, and number of extractions. The suspension was then centrifuged at $3500 \times g$ for $20 \mathrm{~min}$. The aqueous extraction solution was disposed using the Sevage method [33] to remove protein, and then concentrated in a rotary evaporator at $60^{\circ} \mathrm{C}$ under reduced pressure. The aqueous extraction solution protein removed was precipitated by the addition of absolute ethyl alcohol to a final concentration of $80 \%(\% v / v)$ ethanol, and centrifuged again to collect the precipitate. RGP was obtained after freeze drying at $-40{ }^{\circ} \mathrm{C}$ under vacuum.

We determined the polysaccharide sugar content using phenol-sulfuric acid with D-glucose as the standard [34]. The percentage total polysaccharide yield was calculated as follows:

$$
\operatorname{Yield}(\%)=\frac{c W_{2}}{W_{1}} \times 100 \%
$$

where $W_{1}$ is the weight of the Rhizoma gastrodiae residue obtained after extracted three times with $75 \%$ ethyl alcohol (g), $W_{2}$ is the weight of crude RGP (g), and $c$ is the sugar content in the crude RGP (\%).

\subsection{Experimental Design}

Based on the results of the single-factor experiments, the RSM coupled with a three-factor, three-level Box-Behnken design was employed in the optimization procedure [35]. The liquid-to-solid ratio $\left(X_{1}\right)$, extraction temperature $\left(X_{2}\right)$, and extraction time $\left(X_{3}\right)$ were the independent variables, and the polysaccharide yield $(Y)$ was the response variable of the design experiments. The coded levels of the independent variables are displayed in Table 1 . The experiment was carried out at random in 
order to minimize the effect of unexplained variability. The variables were coded according to the following equation:

$$
x_{i}=\frac{X_{i}-X_{0}}{\Delta X}
$$

where $x_{i}$ is the (dimensionless) coded value of the variable $X_{i}, X_{0}$ is the value of $X_{i}$ at the center point, and $\Delta \mathrm{X}$ is the step change.

Experimental data from the Box-Behnken design were fitted to an empirical second-order polynomial model, as follows:

$$
Y=A_{0}+\sum_{i=1}^{3} A_{i} X_{i}+\sum_{i=1}^{3} A_{i i} X_{i}^{2}+\sum_{i=1}^{2} \sum_{j=i+1}^{3} A_{i j} X_{i} X_{j}
$$

where $Y$ is the dependent variable (yield of polysaccharide as a real value), $A_{0}$ is a constant, $A_{i}, A_{i i}$, and $A_{i j}$ are coefficients estimated using the model, and $X_{\mathrm{i}}$ and $X_{\mathrm{j}}$ are levels of the independent variables.

The effect of each independent variable on a response was evaluated using the model. Design-Expert software (version 8.0.6, Stat-Ease Inc., Minneapolis, MN, USA) was used to design the experiment, calculate the predicted data, and estimate the response of the independent variables. Three additional experiments were done under optimal conditions to verify the validity of the model.

\subsection{Purification of RGP}

After the production of RGP under optimal conditions, the crude RGP was dissolved in deionized water $(50 \mathrm{mg} / \mathrm{mL})$ and applied to a DEAE cellulose-52 column $(2.6 \mathrm{~cm} \times 80 \mathrm{~cm})$, which was stepwise eluted with $0,0.1$ and $0.3 \mathrm{M}$ sodium chloride $(\mathrm{NaCl})$ solution at a flow rate of $1 \mathrm{~mL} / \mathrm{min}$. The eluate $(5 \mathrm{~mL} /$ tube) was collected automatically, and the carbohydrate content determined using the phenol-sulfuric acid method. Three completely separated fractions (RGP-1, RGP-2 and RGP-3) were obtained. RGP-1 was applied to a Sephadex G-100 column $(1.8 \mathrm{~cm} \times 100 \mathrm{~cm})$, which was eluted with deionized water at a $0.2 \mathrm{~mL} / \mathrm{min}$ flow rate. The elution was checked as described above. The two purified fractions were collected, concentrated, and lyophilized, thus producing two purified polysaccharides (RGP-1a and RGP-1b) for further study.

\subsection{Characterization of RGP}

\subsubsection{Carbohydrate, Protein and Uronic Acid Determination}

The carbohydrate content of RGP-1a and RGP-1b were determined using the phenol-sulfuric acid method [34] with D-glucose as the standard. Bradford's method was used to measure the protein content [36], with bovine serum albumin as the standard. The uronic acid content was evaluated using the method described by Blumen Krantz and Asboe-Hansen [37], with galacturonic acid as the standard.

\subsubsection{Homogeneity and Molecular Weight Determination}

We analyzed the homogeneity and molecular weight of RGP-1a and RGP-1b using high-performance gel permeation chromatography (HPGPC). The Waters 600 HPLC System (Waters corporation, Milford, MA, USA) equipped with a 2414 differential refractive index detector (RID) and three columns in series (Waters Ultrahydrogel 250, 1000 and 2000; $30 \mathrm{~cm} \times 7.8 \mathrm{~mm} ; 6 \mu \mathrm{m}$ particles) [34]. The columns were calibrated using T-series dextrans (molecular weights 5.2, 10, 48.6, 668 and $2000 \mathrm{kDa}$ ) and eluted with sodium acetate $(3 \mathrm{mM})$ at a flow rate of $0.5 \mathrm{~mL} / \mathrm{min}$. The $\log$ (molecular weight) versus elution time $(t)$ calibration curve was based on the following equation:

$$
\log \left(M_{\mathrm{W}}\right)=-0.136 t+10.94
$$




\subsubsection{Analysis of Monosaccharide Composition}

The RGP-1a and RGP-1b monosaccharide compositions were evaluated using HPLC-RID (LC-15C, Shimadzu, Japan). Briefly, the $200 \mu \mathrm{L}$ polysaccharide solution $(5 \mathrm{mg} / \mathrm{mL})$ was hydrolyzed with $200 \mu \mathrm{L}$ of 4 Mtrifluoroacetic acid (TFA) at $120^{\circ} \mathrm{C}$ for $6 \mathrm{~h}$. After hydrolysis, the solution was evaporated under vacuum. To remove TFA, the residue was dissolved in methanol $(3 \mathrm{~mL})$ and evaporated to dryness. Subsequently, the dried sample was dissolved with $75 \%$ acetonitrile (aq.). Finally, the solution was filtered through a $0.45 \mu \mathrm{m}$ filter and analyzed using HPLC. A Shim-pack CLC- $\mathrm{NH}_{2}$ column was used, and the chromatographic conditions were as follows: column temperature $30^{\circ} \mathrm{C}$, injection volume $20 \mu \mathrm{L}$, mobile phase 75\% acetonitrile (aq.), and a RID-10A refractive index detector (Shimadzu, Japan).

\subsubsection{FTIR Spectrometric Analysis}

We mixed the dried polysaccharides with $\mathrm{KBr}$ powder (spectroscopic grade), then ground and pressed the mixture into pellets $(1 \mathrm{~mm})$ for further FTIR measurement. The IR spectra of RGP-1a and RGP-1b were recorded using a FTIR spectrophotometer (Bruker Tensor 27, Bruker, Germany) the frequency range $400-4000 \mathrm{~cm}^{-1}$.

\subsection{Effect of Polysaccharides on Macrophage Cell}

\subsubsection{RAW 264.7 Cell Viability Assays}

An MTT-based colorimetric method was used to detect the effects of RGP-1a and RGP-1b on RAW 264.7 cell viability [38]. The macrophage cells were placed in 96 -well plates $\left(5 \times 10^{5}\right.$ cells $/$ well $)$ and incubated for $12 \mathrm{~h}$ at $37^{\circ} \mathrm{C}$ in a $5 \% \mathrm{CO}_{2}$ humidified incubator. The medium was then discarded and different concentrations of RGP-1a or RGP- $1 \mathrm{~b}(2.5,5,10,25,50,100,200 \mathrm{and} 400 \mu \mathrm{g} / \mathrm{mL})$ were added to the RAW 264.7 cells. The cells were then incubated for a further $24 \mathrm{~h}$. The medium was used as the blank control. After incubation, MTT solution $(20 \mu \mathrm{L} /$ well $)$ was added to each well, and the cells then incubated for a further $4 \mathrm{~h}$. The supernatant was discarded, $150 \mu \mathrm{L}$ of DMSO was added, and the cells incubated for another $10 \mathrm{~min}$. The absorbance was measured at $570 \mathrm{~nm}$ using a microplate reader (Perlong DNM-9062, Beijing, China).

\subsubsection{Nitric Oxide (NO) Production Assay}

Griess reagent was employed to measure NO production [39]. The RAW 264.7 cells $\left(1 \times 10^{6}\right.$ cells $/$ well $)$ were incubated in a $5 \% \mathrm{CO}_{2}$ humidified incubator for $12 \mathrm{~h}$ at $37^{\circ} \mathrm{C}$. After that, the cells were treated with various concentrations of RGP-1a or RGP-1b $(2.5,10,25,100,200$ and $400 \mu \mathrm{g} / \mathrm{mL})$, and then incubated for a further $24 \mathrm{~h}$. The medium and LPS $(2 \mu \mathrm{g} / \mathrm{mL})$ were used as the blank and positive controls, respectively. After incubation, $100 \mu \mathrm{L}$ of culture supernatant was mixed with an equal volume of Griess reagent in 96-well plates before being incubated in a $5 \% \mathrm{CO}_{2}$ humidified incubator for $10 \mathrm{~min}$ at $25{ }^{\circ} \mathrm{C}$. The absorbance was measured at $540 \mathrm{~nm}$ using a microplate reader. The concentration of nitrite in the culture supernatants was measured to assess the NO production of the RAW 264.7 cells, and the concentrations of $\mathrm{NO}^{2-}$ were determined by least-squares linear regression analysis of the sodium nitrite standard curve.

\subsubsection{Assay of Macrophages Phagocytosis}

The phagocytic ability of RAW 264.7 cells was determined following the uptake of neutral red [37]. Briefly, the cells $\left(1 \times 10^{6}\right.$ cells/well $)$ were dispensed into 96-well plates and incubated for $12 \mathrm{~h}$. The cells were then treated with various concentrations of RGP-1a or RGP-1b $(2.5,10,25,100,200$ and $400 \mu \mathrm{g} / \mathrm{mL})$, and incubated for a further $24 \mathrm{~h}$. The medium and LPS $(2 \mu \mathrm{g} / \mathrm{mL})$ were used as the blank and positive control, respectively. Subsequently, $0.075 \%$ neutral red solution ( $100 \mu \mathrm{L} /$ well) was added to the cells, which were then incubated for $1 \mathrm{~h}$. After wards, the medium was removed and the cells were washed three times with PBS. Cell lysis buffer ( $1 \%$ glacial acetic acid: ethanol = 1:1, 
$100 \mu \mathrm{L} /$ well) was subsequently added for cellysation. After $15 \mathrm{~h}$ incubation at room temperature, the optical density of the cells was measured at $540 \mathrm{~nm}$ using a microplate reader. The phagocytosis index (PI) was determined as per the following equation:

$$
\mathrm{PI}=\frac{A_{1}}{A_{0}}
$$

where $A_{0}$ is the absorbance of the blank control and $A_{1}$ is the absorbance of sample.

\subsection{Statistical Analysis}

All data are presented as means \pm standard deviations. Significant differences between results were examined by ANOVA using SPSS 13.0 (SPSS Inc, Chicago, IL, USA) for Windows. Statistical significance was defined as $p<0.05$ for all tests.

\section{Conclusions}

In the present study, the process for extracting RGP was successfully optimized through a combination of single-factor experiments and RSM. When the extraction was carried out under the optimum process conditions (extraction temperature $74{ }^{\circ} \mathrm{C}$, extraction time $66 \mathrm{~min}$, liquid-to-solid ratio $54 \mathrm{~mL} / \mathrm{g}$, three extractions), a yield of $6.11 \%$ was obtained, which is close to the theoretical yield of $6.15 \%$. Two novel homogeneous polysaccharides (RGP-1a and RGP-1b) with average molecular weights of 19.25 and $3.92 \mathrm{kDa}$, respectively, were purified using DEAE cellulose-52 and Sephadex G-100 columns. The sugar contents of RGP-1a and RGP-1b were $92.53 \%$ and $96.88 \%$, respectively, and no uronic acid or protein was found in the two polysaccharides. RGP-1a is composed of fructose and glucose in a molar ratio of 1:10.68; RGP-1b consists mainly of glucose. In addition, it was found that RGP-1a and RGP-1b have a significant effect on the NO production and phagocytic activity of RAW 264.7 macrophages. RGP-1b showed a stronger effect than RGP-1a, which might be due to the different monosaccharide compositions and structures of the two polysaccharides. However, more research into the structure and mechanism of the biological activities of RGP-1a and RGP-1b is required. Nevertheless, the results of the present study indicated that the use of those two polysaccharides isolated from RGP in health foods has promising prospects.

Acknowledgments: This research was financially supported by the National Natural Science Foundation of China (Grant No. 31270388) and Fundamental Research Funds for the Central Universities In China (Grant Nos QN2011066). Jinyou Duan (Northwest A \& F University, China) is thanked for his help with the immunological activity test.

Author Contributions: Juncheng Chen conducted and performed the experiments; Shan Tian and Xiaoying Shu investigated the biological activities; Hongtao $\mathrm{Du}$ and $\mathrm{Na} \mathrm{Li}$ analyzed the data; Junru Wang designed all the experiments. All authors have read and approved the manuscript.

Conflicts of Interest: The authors declare no conflict of interest.

\section{References}

1. Cheng, J.H.; Lee, S.Y.; Lien, Y.Y.; Lee, M.S.; Sheu, S.C. Immunomodulating activity of Nymphaea rubra Roxb. extracts: Activation of rat dendritic cells and improvement of the $\mathrm{T}_{\mathrm{H}} 1$ immune response. Int. J. Mol. Sci. 2012, 13, 10722-10735. [CrossRef] [PubMed]

2. Shi, M.; Yang, Y.N.; Hu, X.S.; Zhang, Z.Y. Effect of ultrasonic extraction conditions on antioxidative and immunomodulatory activities of a Ganoderma lucidum polysaccharide originated from fermented soybean curd residue. Food Chem. 2014, 155, 50-56. [CrossRef] [PubMed]

3. Yang, L.C.; Hsieh, C.C.; Lin, W.C. Characterization and immunomodulatory activity of rice hull polysaccharides. Carbohydr. Polym. 2015, 124, 150-156. [CrossRef] [PubMed] 
4. Magalhaes, K.D.; Costa, L.S.; Fidelis, G.P.; Oliveira, R.M.; Nobre, L.T.D.B.; Dantas-Santos, N.; Camara, R.B.G.; Albuquerque, I.R.L.; Cordeiro, S.L.; Sabry, D.A. Anticoagulant, antioxidant and antitumor activities of heterofucans from the seaweed Dictyopteris delicatula. Int. J. Mol. Sci. 2011, 12, 3352-3365. [CrossRef] [PubMed]

5. Kurd, F.; Samavati, V. Water soluble polysaccharides from Spirulina platensis: Extraction and in vitro anti-cancer activity. Int. J. Biol. Macromol. 2015, 74, 498-506. [CrossRef] [PubMed]

6. Xie, J.H.; Liu, X.; Shen, M.Y.; Nie, S.P.; Zhang, H.; Li, C.; Gong, D.M.; Xie, M.Y. Purification, physicochemical characterisation and anticancer activity of a polysaccharide from Cyclocarya paliurus leaves. Food Chem. 2013, 136, 1453-1460. [CrossRef] [PubMed]

7. Gao, J.; Zhang, T.; Jin, Z.Y.; Xu, X.M.; Wang, J.H.; Zha, X.Q.; Chen, H.Q. Structural characterisation, physicochemical properties and antioxidant activity of polysaccharide from Lilium lancifolium Thunb. Food Chem. 2015, 169, 430-438. [CrossRef] [PubMed]

8. Chen, Q.; Chen, J.; Du, H.; Li, Q.; Chen, J.; Zhang, G.; Liu, H.; Wang, J. Structural characterization and antioxidant activities of polysaccharides extracted from the pulp of Elaeagnus angustifolia L. Int. J. Mol. Sci. 2014, 15, 11446-11455. [CrossRef] [PubMed]

9. Thambiraj, S.R.; Phillips, M.; Koyyalamudi, S.R.; Reddy, N. Antioxidant activities and characterisation of polysaccharides isolated from the seeds of Lupinus angustifolius. Ind. Crops. Prod. 2015, 74, 950-956. [CrossRef]

10. Nikniaz, Z.; Ostadrahimi, A.; Mahdavi, R.; Ebrahimi, A.A.; Nikniaz, L. Effects of Elaeagnus angustifolia L. supplementation on serum levels of inflammatory cytokines and matrix metalloproteinases in females with knee osteoarthritis. Complement. Ther. Med. 2014, 22, 864-869. [CrossRef] [PubMed]

11. Popov, S.V.; Ovodova, R.G.; Golovchenko, V.V.; Popova, G.Y.; Viatyasev, F.V.; Shashkov, A.S.; Ovodov, Y.S. Chemical composition and anti-inflammatory activity of a pectic polysaccharide isolated from sweet pepper using a simulated gastric medium. Food Chem. 2011, 124, 309-315. [CrossRef]

12. Liu, W.; Zheng, Y.; Zhang, Z.; Yao, W.; Gao, X. Hypoglycemic, hypolipidemic and antioxidant effects of Sarcandra glabra polysaccharide in type 2 diabetic mice. Food Funct. 2014, 5, 2850-2860. [CrossRef] [PubMed]

13. Xv, G.; Jun, M.; Jihai, L.; Bin, T. Hypoglycemic effects of a water-soluble polysaccharide isolated from Schisandra chinensis (Turcz.) Baill in alloxan-induced diabetic mice. J. Biotechnol. 2008, 136, S725. [CrossRef]

14. Ahn, E.K.; Jeon, H.J.; Lim, E.J.; Jung, H.J.; Park, E.H. Anti-inflammatory and anti-angiogenic activities of Gastrodia elata Blume. J. Ethnopharmacol. 2007, 110, 476-482. [CrossRef] [PubMed]

15. Chen, P.J.; Liang, K.C.; Lin, H.C.; Hsieh, C.L.; Su, K.P.; Hung, M.C.; Sheen, L.Y. Gastrodia elata Bl. Attenuated learning deficits induced by forced-swimming stress in the inhibitory avoidance task and Morris water maze. J. Med. Food. 2011, 14, 610-617. [CrossRef] [PubMed]

16. Lee, Y.J.; Hwang, S.M.; Kang, D.G.; Kim, J.S.; Lee, H.S. Effect of Gastrodia elata on tumor necrosis factor-alpha-induced matrix metalloproteinase activity in endothelial cells. J. Nat. Med. 2009, 63, 463-467. [CrossRef] [PubMed]

17. Jung, J.W.; Yoon, B.H.; Oh, H.R.; Ahn, J.-H.; Kim, S.Y.; Park, S.Y.; Ryu, J.H. Anxiolytic-like effects of Gastrodia elata and its phenolic constituents in mice. Biol. Pharm. Bull. 2006, 29, 261-265. [CrossRef] [PubMed]

18. Jang, Y.W.; Lee, J.Y.; Kim, C.J. Anti-asthmatic activity of phenolic compounds from the roots of Gastrodia elata Bl. Int. Immunopharmacol. 2010, 10, 147-154. [CrossRef] [PubMed]

19. Xu, X.; Lu, Y.; Bie, X. Protective effects of gastrodin on hypoxia-induced toxicity in primary cultures of rat cortical neurons. Planta Med. 2007, 73, 650-654. [CrossRef] [PubMed]

20. Yang, X.D.; Zhu, J.; Yang, R.; Liu, J.P.; Li, L.; Zhang, H.B. Phenolic constituents from the rhizomes of Gastrodia elata. Nat. Prod. Res. 2007, 21, 180-186. [CrossRef] [PubMed]

21. Ming, J.; Liu, J.; Wu, S.; Guo, X.; Chen, Z.; Zhao, G. Structural characterization and hypolipidemic activity of a polysaccharide PGEB-3H from the fruiting bodies of Gastrodia elata Blume. Proced. Eng. 2012, 37, 169-173. [CrossRef]

22. Chen, X.; Cao, D.; Zhou, L.; Jin, H.; Dong, Q.; Yao, J.; Ding, K. Structure of a polysaccharide from Gastrodia elata Bl., and oligosaccharides prepared thereof with anti-pancreatic cancer cell growth activities. Carbohydr. Polym. 2011, 86, 1300-1305. [CrossRef]

23. Wang, Y.J.; Cheng, Z.; Mao, J.W.; Fan, M.; Wu, X.Q. Optimization of ultrasonic-assisted extraction process of Poriacocos polysaccharides by response surface methodology. Carbohydr. Polym. 2009, 77, 713-717. 
24. Shao, Q.; Deng, Y.; Fang, H.; Zhao, X. Optimization of polysaccharides extraction from Tetrastigma hemsleyanum Diels et Gilg using response surface methodology. Int. J. Biol. Macromol. 2011, 49, $958-962$. [CrossRef] [PubMed]

25. Xu, Y.; Zhang, L.; Yang, Y.; Song, X.; Yu, Z. Optimization of ultrasound-assisted compound enzymatic extraction and characterization of polysaccharides from blackcurrant. Carbohydr. Polym. 2015, 117, 895-902. [CrossRef] [PubMed]

26. Černá, M.; Barros, A.S.; Nunes, A.; Rocha, S.M.; Delgadillo, I.; Č opìková, J.; Coimbra, M.A. Use of FT-IR spectroscopy as a tool for the analysis of polysaccharide food additives. Carbohydr. Polym. 2003, 51, 383-389. [CrossRef]

27. Del Carmen Juárez-Vázquez, M.; Alonso-Castro, A.J.; García-Carrancá, A. Kaempferitrin induces immunostimulatory effects in vitro. J. Ethnopharmacol. 2013, 148, 337-340. [CrossRef] [PubMed]

28. Zhang, L.; Zhang, W.; Wang, Q.; Wang, D.; Dong, D.; Mu, H.; Ye, X.S.; Duan, J. Purification, antioxidant and immunological activities of polysaccharides from Actinidia Chinensis roots. Int. J. Biol. Macromol. 2015, 72, 975-983. [CrossRef] [PubMed]

29. Beutler, B. Innate immunity: An overview. Mol. Immunol. 2004, 40, 845-859. [CrossRef] [PubMed]

30. Meng, F.-Y.; Ning, Y.-L.; Qi, J.; He, Z.; Jie, J.; Lin, J.-J.; Huang, Y.-J.; Li, F.-S.; Li, X.-H. Structure and antitumor and immunomodulatory activities of a water-soluble polysaccharide from Dimocarpus longan pulp. Int. J. Mol. Sci. 2014, 15, 5140-5162. [CrossRef] [PubMed]

31. Chow, T.N.; Williamson, D.A.; Yates, K.M.; Goux, W.J. Chemical characterization of the immunomodulating polysaccharide of Aloe vera L. Carbohydr. Res. 2005, 340, 1131-1142. [CrossRef] [PubMed]

32. Kouakou, K.; Schepetkin, I.A.; Jun, S.M.; Kirpotina, L.N.; Yapi, A.; Khramova, D.S.; Pascual, D.W.; Ovodov, Y.S.; Jutila, M.A.; Quinn, M.T. Immunomodulatory activity of polysaccharides isolated from Clerodendrum splendens: Beneficial effects in experimental autoimmune encephalomyelitis. BMC Complement. Altern. Med. 2013, 13, 1-19. [CrossRef] [PubMed]

33. Navarini, L.; Gilli, R.; Gombac, V.; Abatangelo, A.; Bosco, M.; Toffanin, R. Polysaccharides from hot water extracts of roasted Coffea arabica beans: Isolation and characterization. Carbohydr. Polym. 1999, 40, 71-81. [CrossRef]

34. Dubois, M.; Gilles, K.A.; Hamilton, J.K.; Rebers, P.; Smith, F. Colorimetric method for determination of sugars and related substances. Anal. Chem. 1956, 28, 350-356. [CrossRef]

35. Ahmad, A.; Alkharfy, K.M.; Wani, T.A.; Raish, M. Application of Box-Behnken design for ultrasonic-assisted extraction of polysaccharides from Paeonia emodi. Int. J. Biol. Macromol. 2015, 72, 990-997. [CrossRef] [PubMed]

36. Bradford, M.M. A rapid and sensitive method for the quantitation of microgram quantities of protein utilizing the principle of protein-dye binding. Anal. Biochem. 1976, 72, 248-254. [CrossRef]

37. Blumenkrantz, N.; Asboe-Hansen, G. New method for quantitative determination of uronic acids. Anal. Biochem. 1973, 54, 484-489. [CrossRef]

38. Mosmann, T. Rapid colorimetric assay for cellular growth and survival: Application to proliferation and cytotoxicity assays. J. Immunol. Methods 1983, 65, 55-63. [CrossRef]

39. Bo, R.; Ma, X.; Feng, Y.; Zhu, Q.; Huang, Y.; Liu, Z.; Liu, C.; Gao, Z.; Hu, Y.; Wang, D. Optimization on conditions of Lycium barbarum polysaccharides liposome by RSM and its effects on the peritoneal macrophages function. Carbohydr. Polym. 2015, 117, 215-222. [CrossRef] [PubMed]

(C) 2016 by the authors; licensee MDPI, Basel, Switzerland. This article is an open access article distributed under the terms and conditions of the Creative Commons Attribution (CC-BY) license (http://creativecommons.org/licenses/by/4.0/). 